\title{
EL BIENESTAR SUBJETIVO COMO ENFOQUE E INSTRUMENTO DE LA POLÍTICA PÚBLICA: UNA REVISIÓN ANALÍTICA DE LA LITERATURA
}

\author{
Roberto Castellanos Cereceda \\ Universidad Nacional Autónoma de México \\ rcastellanos@comunidad.unam.mx
}

En este trabajo se analiza la utilidad que tiene el enfoque del bienestar subjetivo para el estudio, análisis y hechura de la política pública. Se sostiene que el enfoque de bienestar subjetivo ofrece nuevas formas para poner a prueba supuestos básicos del análisis económico y social sobre el comportamiento humano; ofrece herramientas de análisis que dan una perspectiva diferente y complementaria a mediciones y enfoques tradicionales sobre los aspectos que más importan a la población en su proceso de desarrollo; así como también provee un conjunto de reflexiones importantes sobre las implicaciones del estudio de la felicidad y la satisfacción de vida para diferentes tipos de políticas públicas y en distintos ámbitos de la acción gubernamental. Estos aspectos se analizan a partir de un rastreo histórico sobre los orígenes del estudio sistemático del bienestar subjetivo y de una revisión de la literatura para identificar temas abordados, herramientas desarrolladas y políticas públicas implicadas.

Palabras clave: Bienestar subjetivo, políticas públicas, gobierno. 


\section{SUBJECTIVE WELLBEING AS A PUBLIC POLICY APPROACH AND INSTRUMENT: AN ANALYTIC LITERATURE REVIEW}

In this paper we analyze the utility that the subjective wellbeing approach brings to the study, analysis and design of public policy. It argues that the subjective wellbeing approach offers new ways to test basic assumptions of the economic and social analysis of human behavior; offers analytical tools that provide a different and complementary perspective to traditional measures and approaches regarding the aspects that matter most to the population in their development process; and provides a set of important reflections regarding the implications of the study of happiness and life satisfaction for different types of public policy and in different fields of government action. These aspects are analyzed through a historical tracing of the origins of the systematic study of subjective wellbeing and a literature review to identify issues addressed, tools developed and public policies involved.

Keywords: Subjective wellbeing, public policy, government 


\section{INTRODUCCIÓN}

¿Pueden los gobiernos influir en la felicidad de la población e incrementarla? ¿Deberían hacerlo si pueden? ¿En qué ámbitos de la vida de las personas y las sociedades sí pueden incidir los gobiernos para ampliar la felicidad de la población o las condiciones para que ésta pueda alcanzarla? ¿Con qué herramientas de política pública y capacidades cuentan los gobiernos? Desde los clásicos griegos, hasta los filósofos e intelectuales del siglo XVIII y XIX, y en décadas recientes, la comunidad académica, gobiernos nacionales y organismos internacionales, han buscado dar respuesta a estas interrogantes. La literatura académica de los pasados 20 años, y en especial de la primera década del siglo XXI, ha aportado evidencia rigurosa y abundante sobre los alcances y límites del uso del enfoque del bienestar subjetivo y la felicidad ${ }^{1}$ para la acción pública. La búsqueda individual y colectiva de la felicidad, planteada desde la Grecia clásica como una reflexión y aspiración vitales, se ha convertido en objeto de estudio y motivo de indagación científica en la psicología, la economía, la sociología, la neurología, entre otras ciencias. Tan sólo en el último lustro, la atención a la felicidad y a la satisfacción de vida ha pasado de los laboratorios, foros y encuentros académicos, a las oficinas de estadística de los gobiernos y a la discusión sobre política pública. En la actualidad existen poco más de una decena de iniciativas de gobiernos nacionales interesados en medir el bienestar subjetivo de la población y en usar esa información para tomar decisiones de política pública.

Tomando en cuenta la multiplicidad de preguntas, debates abiertos e iniciativas en marcha sobre el bienestar subjetivo y su uso en las políticas, en este artículo se busca responder a la siguiente pregunta: ¿Qué utilidad tiene el enfoque del bienestar subjetivo para el estudio, análisis y hechura de la política pública? El propósito es comprender los siguientes aspectos específicos: (a) ¿Cuál es la relevancia teórica y práctica que tiene para la política pública el estudio y análisis del bienestar subjetivo de la población? (b) ¿Cuáles son las herramientas analíticas que el enfoque de bien-

1 A lo largo de este texto se emplean los términos "bienestar subjetivo", "felicidad" y "satisfacción de vida" de forma más o menos similar y por tanto intercambiable. No obstante, como se verá más adelante, satisfacción de vida, felicidad y eudemonismo son términos que forman parte complementaria del concepto de bienestar subjetivo. Estos términos tienen definiciones diferentes en la literatura (las cuales, incluso, adquieren matices dependiendo del autor de que se trate), pero comparten un mismo referente: el reconocimiento de la importancia y el interés en indagar en la valoración que las personas hacen (subjetividad) sobre el estado que guarda su bienestar. 
estar subjetivo aporta para la política pública? (c) ¿Cuáles son los ámbitos temáticos o sectores de política pública en los que se han realizado estudios sobre bienestar subjetivo y sus implicaciones de política pública?, y (d) ¿Cuáles son los principales retos y limitaciones del uso del enfoque de bienestar subjetivo para el análisis de políticas? Las respuestas a estas interrogantes se sustentan en la revisión de la literatura académica relevante en la materia, principalmente de los pasados 20 años, periodo en el que se aprecia un crecimiento sustancial en el interés en el bienestar subjetivo. El artículo se integra en las siguientes secciones. En la sección uno se analiza los orígenes del estudio del bienestar subjetivo, rastreo histórico que ofrece pistas sobre la motivación de informar la política pública desde que se hicieran las primeras investigaciones en el tema. En la sección dos se presenta algunas de las principales definiciones sobre bienestar subjetivo identificadas en la literatura, con el fin de dar cuenta de la diversidad de significados que ha adquirido el concepto de bienestar subjetivo y para mostrar que la falta de consenso sobre una definición no ha obstaculizado el avance de esta sub-disciplina en el desarrollo de herramientas analíticas e instrumentos de medición. En la sección tres del artículo se argumenta cuál es la utilidad del enfoque de bienestar subjetivo para la política pública, tomando en cuenta las paradojas que plantea y que han abierto nuevas rutas de indagación en la economía y otras ciencias del comportamiento humano; las herramientas de análisis que se han desarrollado; el tipo de políticas públicas que puede contribuir a informar el enfoque de satisfacción de vida y felicidad, y los retos y limitaciones que se deben tomar en cuenta al considerar las implicaciones de política pública de los estudios elaborados en este ámbito disciplinario. En la cuarta y última sección se presentan las conclusiones del trabajo.

\section{El bienestar SUbJeTIVO: ORÍGENES y RAZONES PARA SU ESTUdio}

En este apartado se abordan, de forma breve, los orígenes históricos del concepto de bienestar subjetivo. Los antecedentes históricos son pertinentes en la medida en que contextualizan y dan sentido a los debates sobre la utilidad del bienestar subjetivo en la política pública y permiten comprender cómo es que, desde sus inicios, el estudio del bienestar subjetivo ha sido parte de la investigación aplicada en diferentes disciplinas y ha partido de un interés en generar conocimiento, 
herramientas analíticas e informar la toma de decisiones de gobierno para mejorar el bienestar de las sociedades. Es decir, la investigación sobre bienestar subjetivo ha tenido desde sus orígenes una orientación aplicada.

\section{Orígenes históricos del enfoque de bienestar subjetivo}

Hasta antes del siglo XX, la felicidad era un ámbito de reflexión casi exclusivamente de la filosofía. Jeremy Bentham (1789), uno de los autores con los que mayormente se asocia el origen del estudio del bienestar subjetivo y del bienestar en general, específicamente en el terreno de la economía, fue un filósofo británico cuya obra dio origen al "utilitarismo". Bentham argumentó que el fin último del gobierno debía ser el lograr la mayor felicidad para el mayor número de personas en una sociedad.

Los primeros esfuerzos por comprender la felicidad y el bienestar subjetivo usando instrumentos de medición para conocer sus niveles, indagar de forma sistemática sus posibles relaciones causales con el comportamiento humano y darles seguimiento en el tiempo, tuvieron lugar en la segunda década del siglo XX. A partir de ese momento se comenzaron a sentar las bases de lo que algunos han dado en llamar la "ciencia dela felicidad", para hacer referencia al conjunto de indagaciones y generalizaciones empíricas y teóricas sustentadas en mediciones subjetivas orientadas a la comprensión de los factores que influyen en el bienestar de las personas (Layard, 2005; Angner, 2011)2 . Tomando en cuenta las aportaciones a la historia de la felicidad hechas por Angner (2011), S. Bok (2010), Cobb y Rixford (1998), entre otros, se pueden distinguir al menos tres periodos históricos: (1) las décadas de 1920 y 1950, época en la que el estudio del bienestar subjetivo se abordó casi de forma exclusiva desde la psicología; (2) las décadas de 1960 y 1970, con el surgimiento del Movimiento de Indicadores Sociales que llevó a las ciencias sociales la discusión sobre el bienestar subjetivo y su relevancia como enfoque para medir el avance de las sociedades; (3) y el periodo que inicia en la década de 1970, específicamente con la publicación del trabajo de Richard Easterlin (1974) y que continúa en la década de 1990 y del 2000, con el crecimiento exponencial en el número de publicaciones, informes y debates sobre el tema, con un marcado predominio de análisis desde la economía. Esta última es también

2 De acuerdo con Angner (2011:2), la aparición de la ciencia de la felicidad estaría marcada por un artículo publicado en 1917, de un autor llamado A. Myerson, que promovía la disciplina de la "eupatía" (euphatics). 
la época en que se aprecia el mayor interés en el tema al interior de los gobiernos y organismos internacionales, derivando en muchos casos en el impulso de iniciativas específicas de medición del bienestar subjetivo y esfuerzos concretos por incorporarlas en la toma de decisiones de la política pública ${ }^{3}$. En el resto de este apartado se analizan los principales rasgos de estas tres etapas históricas.

\section{(a) El bienestar subjetivo como materia de estudio de la psicología}

Los primeros esfuerzos por hacer uso del enfoque de bienestar subjetivo y construir instrumentos para medirlo surgieron en la psicología y fueron aplicados en las décadas de 1920 y 1930 en estudios sobre las relaciones matrimoniales, la psicología educativa y la psicología de la personalidad. En estos estudios se aplicaban encuestas en las que se preguntaba a los participantes si consideraban su vida feliz, satisfactoria, exitosa o no.

En el ámbito de la psicología educativa, por ejemplo, destaca un estudio a cargo de Goodwin Watson, 1930 (citado en Angner, 2010), cuyo objetivo era conocer la felicidad entre estudiantes de educación de la Universidad de Columbia. Después de éste, otros trabajos analizaron la relación entre diferentes aspectos de la personalidad y los niveles de felicidad de las personas. Estos trabajos formaron parte de la sub-disciplina conocida como psicología de la personalidad y gracias al cuerpo de conocimientos que dieron forma a esta sub-disciplina, los psicólogos concluyeron que era confiable y válido medir atributos de la personalidad de forma directa y por medio de preguntas hechas a las personas, como la felicidad. Concluyeron también que los resultados de sus investigaciones podrían ser de utilidad para los gobiernos.

Fue en esta época que se diseñó el "euforímetro" (traducción libre de la palabra Euphorimeter), una escala que permitía medir, de forma similar a un termómetro, la felicidad y "las causas de la angustia humana" (Hart, 1940). De acuerdo con Hornell Hart, autor de esta escala, el euforímetro tenía como fin "señalar el

3 La clasificación histórica que se propone aquí y las fuentes de información que se emplearon para la separación de las etapas, consideran fundamentalmente el desarrollo del estudio del bienestar subjetivo en Estados Unidos y en países de Europa. Esto es así debido a las fuentes de información consultadas sobre la materia, y a que, si bien la felicidad no es, por supuesto, una preocupación exclusiva de la comunidad académica e intelectual en Estados Unidos o en países europeos, el estudio sistemático y la construcción de conocimiento sobre el bienestar subjetivo se ubica, de forma predominante, en esos países y regiones, a los que, en décadas recientes, se han incorporado otros, como Australia, Bután, Canadá, Chile, Japón, México, entre otros. 
camino, no para la administración de drogas [que aumentaran o disminuyeran la felicidad], sino para establecer mediciones constructivas que puedan aliviar desajustes, promover la cura del sufrimiento mental y abrir el camino hacia una vida más alegre" (Hart, 1940). Dado que la felicidad podía fluctuar de un momento a otro, Hart diseñó dos euforímetros, uno para medir la felicidad de forma inmediata o "en el momento" y otro para medir el nivel general de (in)felicidad en el largo plazo. Esta fue una de las primeras propuestas de medición que distinguían entre "felicidad inmediata", asociada sobre todo con la experiencia emotiva más cercana y con la ausencia o presencia de placer y dolor, y la "satisfacción de largo plazo", vinculada con una evaluación de la vida en su conjunto.

En la década de 1950 y en los inicios de 1960, las mediciones de bienestar subjetivo se expandieron a las áreas de la salud mental y la gerontología, y en el caso de la salud mental, comenzaron a emplear mediciones de felicidad y satisfacción de vida aplicadas a muestras representativas de amplios sectores de la población. Lo que interesaba a los autores de la época era de qué forma las personas percibían su salud mental, en contraste con la visión de los expertos en la materia, y también enfatizaron la importancia de la salud mental en la felicidad.

\section{(b) El Movimiento de Indicadores Sociales}

Luego de la Gran Depresión de 1929 y de los devastadores efectos financieros de la Segunda Guerra Mundial, el principal objetivo de la política pública en los años siguientes fue el impulso al empleo y al crecimiento económico, para lo cual se desarrollaron algunos de los indicadores económicos claves que se emplean hasta la actualidad, como la tasa de desempleo y el Producto Nacional Bruto, propuesto este último por Simon Kuznets y diseñado en gran medida como un instrumento para organizar la producción en tiempos de guerra (Cobb y Rixford, 1998; Haggart 2000) ${ }^{4}$. Para la década de 1960, si bien el crecimiento económico y el desempleo seguían siendo una preocupación de los gobiernos y de la comunidad

4 Kuznets propuso al Congreso de los Estados Unidos medir el valor económico agregado de los bienes y servicios producidos por aquel país como un instrumento que permitiera tener mayor conocimiento y control sobre la actividad económica, pero también afirmó que el producto nacional bruto (PNB) era una medición limitada para capturar todas las actividades relevantes en la economía y por tanto era incorrecto considerarla una medida de bienestar económico. De hecho, rompió relaciones con el Departamento de Comercio del Gobierno de Estados Unidos, luego de que éste se negara a incorporar en el PNB la estimación del trabajo doméstico no pagado, que Kuznets consideraba fundamental (Rowe, 2008). 
intelectual, otros temas emergieron en la agenda pública: problemas de naturaleza no sólo económica, de ingresos y producción, sino social, como la provisión de servicios de salud y educativos, la pobreza y la desigualdad, el desarrollo urbano, entre otros. En este contexto surge, primero en Estados Unidos y luego en Europa, el Movimiento de Indicadores Sociales, como una reacción al uso extendido de indicadores económicos como el PIB para medir el bienestar y desarrollo de las sociedades, así como una llamada de atención a la necesidad de atender y medir problemas sociales emergentes (Cobb y Rixford, 1998; Angner, 2010).

De acuerdo con uno de los promotores del Movimiento de Indicadores Sociales, se buscaba introducir dos cambios en las prácticas de recolección, diseño y uso de indicadores. Primero, "ampliar el rango de fenómenos monitoreados más allá de los indicadores económicos tradicionales, y el reconocimiento explícito de que la 'calidad de vida', como sea que se le defina, supone más que sólo consideraciones económicas", y segundo, "enfocarse de forma directa en indicadores de resultado [outcome], es decir, indicadores que muestren qué tanto ha mejorado una persona, además de los indicadores de insumo [input]más tradicionales, que reflejan las asignaciones presupuestales, los procedimientos y procesos que se requieren para mejorar el bienestar" (Andrews, 1989, en: Angner, 2010:23).

En sus inicios, el Movimiento de Indicadores Sociales insistió en que en el diseño de las políticas públicas se incorporaran indicadores como acceso a vivienda, atención médica, educación, esperanza de vida y calidad del agua. Pero más tarde se consideró que estos indicadores no eran suficientes, porque seguían siendo de insumo y no de resultado. De ahí surgió la atención a indicadores de tipo subjetivo, los cuales, si bien no se consideraban "tan precisos como aquellos que se expresan en dólares... sí tienen la gran ventaja de que abordan de forma directa lo que queremos saber, la sensación de bienestar de los individuos"s, y en ese sentido constituían indicadores de resultado, al captar el efecto de las políticas públicas en la calidad de vida de los individuos (Campbell, 1976, en: Angner, 2010:24). Desde entonces, se ha defendido la idea de que la medición del bienestar subjetivo tiene entre sus fortalezas el ser más directa (no es un experto el que decide qué es importante, sino que se le pregunta a las personas) y enfocarse en los resultados

5 El énfasis es nuestro. 
que las políticas públicas o las condiciones de vida tienen sobre el bienestar de las personas y las sociedades.

\section{(c) De la paradoja de Easterlin a la felicidad como objeto de las politicas}

En 1974, el autor Richard Easterlin se planteó una pregunta: ¡el aumento en el ingreso incrementa el bienestar subjetivo de la población? Su respuesta derivó en una aparente paradoja: a medida que los países incrementan sus niveles de ingreso per cápita, los niveles promedio de bienestar subjetivo no aumentan, sino que muestran rendimientos marginales decrecientes, lo que contradice la lógica que supone que el bienestar depende en gran medida de los niveles de ingreso de los individuos y las sociedades. El análisis de Easterlin atrajo poco la atención en su momento, pero desde la década de 1990 ha sido citado, analizado, refutado y revisitado por otros y por el propio autor, de manera que se le puede considerar como el análisis que da inicio al periodo de mayor productividad e intensidad intelectual sobre el bienestar subjetivo desde sus primeras aplicaciones en la psicología en la década de 1920. ¿Por qué resulta tan importante el trabajo de Easterlin? El análisis de este autor aportó cifras y argumentos sistemáticos de que el desarrollo de las sociedades no depende sólo del crecimiento de su ingreso. Easterlin muestra en su análisis que a pesar de haber alcanzado niveles de ingreso y crecimiento no vistos antes en la historia documentada de la humanidad, los individuos y las sociedades no han logrado mejorar su calidad de vida y en particular la percepción que tienen del progreso y bienestar que han alcanzado.

Más recientemente, el creciente interés en el estudio del bienestar subjetivo se aprecia en el número de artículos académicos publicados hasta el año 2000 que abordan el tema: 4.351 (Veenhoven 2007, en: Johns y Ormerond, 2007:19); aunque la mayor intensidad en el crecimiento de la producción de artículos sobre bienestar subjetivo se ha dado en la década pasada. Como muestra de ello está la revista Journal of Happiness Studies. An interdisciplinary forum on subjective wellbing, publicación arbitrada que se edita en Estados Unidos desde marzo del año 2000 de forma bimensual.

A la par de la generación de conocimiento teórico y empírico sobre el bienestar subjetivo, en los últimos 10 años se ha hecho evidente el amplio interés entre organizaciones internacionales y gobiernos para medir el bienestar subjetivo y considerar su inclusión en decisiones de gobierno. En junio de 2007, en el marco de 
una conferencia internacional organizada por la Organización para la Cooperación y el Desarrollo Económicos (OCDE), se suscribió la Declaración de Estambul, que estableció un conjunto de metas para identificar nuevas mediciones que fueran "más allá del PIB”. La Declaración de Estambul incorporó las discusiones sobre el desarrollo de mediciones de bienestar subjetivo en la agenda pública internacional, como parte del marco más amplio de los debates sobre calidad de vida y nuevas formas de medir el progreso de las sociedades (OCDE 2007).

Otro momento clave fue la creación, bajo los auspicios del gobierno de Francia, de la Comisión sobre la Medición del Desempeño Económico y el Progreso Social, a cargo de los premios Nobel de economía Joseph Stiglitz y Amartya Sen, y de Jean-Paul Fitoussi. La Comisión se propuso "identificar los límites del PIB como indicador de desempeño económico y progreso social, incluyendo los problemas de medición; considerar qué información adicional puede ser requerida para la producción de indicadores de progreso social más relevantes; evaluar la viabilidad de herramientas de medición alternativas y discutir cómo presentar la información estadística de forma apropiada” (Stiglitz et al., 2009). En su reporte final, la Comisión reconoce que tanto las mediciones de bienestar objetivo como subjetivo ofrecen información clave sobre la calidad de vida de las personas, y recomienda: "las oficinas [nacionales] de estadística deben incorporar en sus encuestas preguntas que permitan capturar las evaluaciones que las personas hacen de su vida, sus experiencias hedónicas y sus prioridades de vida” (Stiglitz et al., 2009:16).

En una línea similar, el 19 de julio de 2011, la 65ª Asamblea General de las Naciones Unidas votó de forma unánime una resolución que invita a los Estados parte a que "elaboren mediciones adicionales que capturen de una mejor forma la importancia de la búsqueda de la felicidad y el bienestar en el desarrollo, con miras a que sean una guía de sus políticas públicas" (Asamblea General de Naciones Unidas, 2011). La resolución fue promovida por el gobierno de Bután, el cual posee una medición nacional oficial, el índice de Felicidad Nacional Bruta (Ura et al., 2012), que incorpora, entre otros, indicadores sobre satisfacción y felicidad de la población, además de indicadores objetivos, incluyendo el ingreso.

En la actualidad, más de una decena de países, principalmente desarrollados y de Europa, están llevando a cabo iniciativas de medición del bienestar subjetivo a cargo de las oficinas de estadística nacional. En algunos casos, como en el Reino 
Unido, se están construyendo las bases para establecer un sistema de medición que permita hacer uso de las mediciones en el diseño de políticas públicas (ONS, 2011; OCDE, 2011) ${ }^{6}$.

La medición del bienestar subjetivo proviene de una larga tradición originada en la filosofía y más recientemente en la psicología y las ciencias sociales aplicadas. Tanto en su uso y análisis actual como en sus orígenes históricos, el bienestar subjetivo ha sido empleado en distintas disciplinas, pero con un rasgo en común: su orientación aplicada. Las mediciones de bienestar subjetivo se desarrollaron en el ámbito de las ciencias sociales aplicadas más que en ramas teóricas de esas disciplinas, lo que está asociado con el impulso de la comunidad intelectual y académica de contribuir a la construcción de mejores individuos y en general de una mejor sociedad. En muchos sentidos, el logro y parte del atractivo de la investigación reciente sobre el bienestar subjetivo es que ha incorporado evidencia empírica en debates filosóficos que se remontan a Aristóteles y más recientemente a Jeremy Bentham, y al ofrecer esa evidencia ha contribuido a esclarecer algunos de esos debates y a plantear nuevas interrogantes (Bok, 2010). A su vez, esto ha contribuido a construir una masa crítica de conocimientos que han ayudado a promover la medición del bienestar subjetivo desde los gobiernos y a analizar las posibilidades e implicaciones de su uso en la política pública.

\section{2. ¿QUÉ ES EL BIENESTAR SUBJETIVO?}

En este apartado analizo de forma sintética las definiciones de bienestar subjetivo que se emplean comúnmente en la literatura académica y en los debates de política pública sobre el tema. Dada la amplia diversidad de posturas y definiciones que existen desde la antigüedad sobre lo que constituye la felicidad y el bienestar subjetivo, hacer un recuento puntual de ellas escapa a los objetivos de este trabajo, por lo que analizo sólo algunas de las definiciones más distintivas7. El análisis

6 Asimismo, organismos internacionales como la OCDE y diversas organizaciones ciudadanas de alcance internacional, como New Economics Foundation, han venido impulsado discusiones sobre las formas de medición del bienestar subjetivo y sus aportaciones a la acción pública de gobierno por medio de foros, encuentros y reportes periódicos inscritos en el marco más amplio del debate sobre el rumbo y medición del progreso.

7 Por ejemplo, S. Bok (2010) hace un recuento exhaustivo sobre las posturas y definiciones filosóficas de la felicidad desde los filósofos griegos y discute algunas de sus diferencias y similitudes más destacadas. 
de las diferentes definiciones sobre bienestar subjetivo también arroja luz sobre un aspecto relevante para el objetivo de este trabajo: las divergencias sobre una definición compartida y de uso generalizado de bienestar subjetivo no han obstaculizado el avance en el conocimiento empírico en la materia y en su medición. El acuerdo en torno al bienestar subjetivo, sin ser unívoco ni consensual, se ha concentrado en mayor medida en los instrumentos de medición disponibles y en los aportes a la política pública. Ello ha permitido ir construyendo un cuerpo de conocimiento coherente, con resultados comparables en el tiempo y de utilidad para informar la política pública.

Uno de los primeros filósofos en reflexionar sobre el significado y alcance de la felicidad fue Aristóteles, quien sostuvo que la felicidad o eudaimonia era el bien humano más importante y un asunto de virtud: la expresión racional de la actividad virtuosa del alma a lo largo de toda una vida (Bok, 2010). Esta definición tiene al menos dos implicaciones, una de las cuales abre una pregunta que se mantiene vigente hasta la actualidad, al menos en el terreno de la investigación sobre bienestar subjetivo. En primer lugar, si la felicidad es un asunto de virtud, eso supone que la fuente de la auténtica felicidad sólo puede provenir de actividades o deseos considerados virtuosos, de manera que si una actividad genera placer o gozo pero no se aprecia como una virtud, no puede considerarse como fuente de felicidad. En segundo lugar, Aristóteles enfatiza que la felicidad sólo se puede valorar tomando en cuenta el conjunto de la vida de una persona, no sólo una parte de ella y mucho menos un momento específico. En síntesis, la felicidad o eudaimonia, a la que también se le equipara con el concepto de "florecimiento humano", es el resultado de una vida virtuosa, independiente de la búsqueda y obtención de placer (Haybron, 2011).

Varios siglos después, en la época de la Ilustración, Jeremy Bentham (1789) propuso una definición de felicidad y bienestar cualitativamente diferente a la de Aristóteles al afirmar en su obra Introducción a los principios de la moral y la legislación que la felicidad es la suma de los placeres y dolores de los individuos. Bentham se ubica en una postura que destaca la dimensión afectiva e incluso física o sensorial de la felicidad. Si bien las definiciones de Aristóteles y Bentham se pueden ubicar, de forma más o menos clara, aunque esquemática, en los extremos de las posturas sobre qué es la felicidad y el bienestar subjetivo, conviene considerar que para Bentham la suma de los placeres y dolores constituía algo 
más complejo que sólo una mezcla de sensaciones. Bentham afirmaba que existen cuatro fuentes de dolor y placer: la física, la política, la moral y la religiosa. El solo hecho de establecer una clasificación de fuentes de placer y dolor, supone que las emociones que aumentan o disminuyen la felicidad provienen de procesos cognitivos complejos, de una evaluación racional que distingue entre diferentes dominios de vida (Ott, 2010:632).

Buscando encontrar un significado compartido entre las definiciones de filósofos de diferentes épocas sobre lo que es la felicidad, McGill (1967, citado en: S. Bok, 2010:622) argumenta que el significado común en la mayoría de las definiciones es el siguiente: "Un estado de cosas perdurable en el que se alcanza la relación más favorable entre deseos satisfechos y deseos [anhelados]". Desde la psicología, Hart (1940) afirmaba que la felicidad es cualquier estado consciente que una persona busca alcanzar, o permanecer en él, opuesto a cualquier estado en el que, quien lo experimenta, busca cambiar o escaparse de él. Estudiosos de la salud mental de la década de 1960 concluyen que la felicidad es el resultado de las fortalezas relativas de sentimientos positivos y negativos, más que de la cantidad absoluta de uno $\mathrm{u}$ otro de estos sentimientos (Bradburn y Caplovitz, 1965, en: Angner, 2011). A la luz de estas aportaciones, se ha sugerido que el bienestar subjetivo debe ser visto como el resultado de tres componentes: la presencia predominante de sentimientos positivos, la ausencia o presencia no predominante de sentimientos negativos y la satisfacción con la vida, esta última como una valoración cognitiva y de amplio espectro temporal sobre las condiciones de vida de la persona. En tiempos más actuales, pero en una línea de reflexión similar, Richard Layard, uno de los principales promotores del enfoque de bienestar subjetivo y de su uso en la política pública, afirma, invocando a Jeremy Bentham, que la felicidad es "un sentimiento grato, el disfrute de la vida y el deseo de que este disfrute se mantenga" (Layard, 2005:12).

Sin abandonar por completo el debate sobre qué es la felicidad, la investigación y discusión pública sobre el bienestar subjetivo durante los pasados 30 años se ha concentrado de forma predominante en encontrar la mejor manera de medir este tipo de bienestar. Por tanto, a partir del tipo de medición elegida se puede derivar el concepto de felicidad que cada autor emplea. Por ejemplo, para Ed Diener (2000) la felicidad o bienestar (wellbeing) se define a partir de la pregunta o preguntas que se les hace de forma directa a las personas sobre su nivel de satisfacción con la vida o de felicidad: "Es este enfoque para definir una buena vida el que se 
ha denominado bienestar subjetivo y que de forma coloquial a veces se le llama felicidad" (Diener, 2000:34).

En la actualidad existe una posición relativamente amplia de que el bienestar subjetivo debe comprender al menos dos dimensiones o componentes, soportadas en dos acercamientos distintos, pero complementarios, para medirlas, pero también existe un aproximación adicional, la del eudemonismo, que se acerca más a la idea aristotélica de felicidad. La primera dimensión (y su medición) busca capturar la evaluación que las personas hacen de sus vidas en general, y se conoce como satisfacción de vida o componente cognitivo. La segunda dimensión o componente del bienestar subjetivo es la felicidad, definida como experiencia afectiva, componente hedónico que se enfoca en las emociones y sentimientos experimentados. Una tercera dimensión, conceptualmente más cercana a la de satisfacción de vida que a la de felicidad, es el eudemonismo, la cual se refiere a la satisfacción de necesidades vitales y psicológicas básicas, a la percepción que tengan las personas de que su proyecto vital es valioso y que puedan llevarlo a cabo con márgenes suficientes de autonomía. Estas definiciones o acercamientos para medir el bienestar subjetivo reflejan la noción de que la forma en que las personas experimentan una serie de circunstancias es tan importante como las circunstancias mismas y que las personas son los mejores jueces para evaluar cómo son sus vidas (OCDE, 2011). En los estudios sobre bienestar subjetivo existe una inclinación para considerar en mayor medida la dimensión de satisfacción de vida pero para algunos autores estas tres dimensiones, especialmente las de satisfacción de vida y felicidad, son inseparables: un individuo puede hacer una evaluación muy favorable de su vida en general, reflejando quizá una personalidad optimista, aunque en su vida cotidiana se enfrente a un número reducido de placeres satisfechos y un mayor número de experiencias difíciles o poco satisfactorias.

En el recuento de definiciones y posturas sobre qué es el bienestar subjetivo y la felicidad cabe mencionar el surgimiento de enfoques que, desde una perspectiva sociológica, enfatizan la necesidad de analizar en qué medida el bienestar subjetivo de las personas incorpora una reflexión sobre la posibilidad real de elegir entre diferentes opciones de vida. Millán (2011:25) argumenta a favor de esta incorporación reflexiva de las opciones de vida reales que tienen las personas porque de esta forma se puede "identificar si lo que fundamenta la valoración de la felicidad, o la satisfacción, cualquiera que sea la razón, es electivo o no". Esta 
dimensión reflexiva concreta permite saber en qué medida las opciones objetivas, teórica y empíricamente disponibles, de los individuos, son opciones valoradas subjetivamente como posibles o materializables por ellos mismos. Esto es importante porque esas opciones valoradas subjetivamente como realizables influyen en el bienestar subjetivo y en las decisiones individuales. Así, el bienestar subjetivo estaría asociado con el hecho de que una persona incorpore de forma reflexiva un número limitado de opciones de vida, que considere que dichas opciones están a su alcance, y por lo tanto sean realmente opciones.

La incorporación de la reflexividad en el análisis del bienestar subjetivo es un asunto destacado: la necesidad de que la felicidad esté sustentada en la libertad del individuo de elegir entre opciones de vida que estén subjetivamente incorporadas a partir del "catálogo de opciones" que objetivamente estén a su alcance y que se encuentran, en cierto sentido, influidas por las condiciones objetivas de vida en las que se encuentra una persona y el grupo social al que pertenece ${ }^{8}$. Una implicación adicional, es que la dimensión reflexiva lleva a favorecer la medición de la dimensión satisfacción de vida, dado que acentúa una evaluación sobre la vida de las personas que es más cognitiva que emotiva; aunque los resultados de esta medición y la de afección o felicidad arrojan resultados similares en muchos estudios, por lo que no son por completo separables y se pueden usar de forma indistinta (Millán 2010:25).

Finalmente, la reflexividad sobre opciones de vida parece retomar la posición aristotélica sobre la existencia de diferentes cualidades de felicidad, es decir, no todas las formas y fuentes de felicidad son iguales, algunas pueden ser mejores o más auténticas que otras. Desde esta óptica, la felicidad "buena" o "auténtica" sería aquella en que la satisfacción de vida se sustenta en un ejercicio de reflexividad sobre la posibilidad real de construir sentido (una opción de vida) de entre

8 La reflexividad como elemento conceptual constitutivo del bienestar subjetivo planteado por Millán tiene similitudes con la definición de subjetividad que introduce el PNUD Chile en su informe de 2012 sobre Desarrollo Humano en ese país, en el que analiza precisamente al bienestar subjetivo como una oportunidad para repensar el desarrollo. En el informe, el PNUD (2012:16) define la subjetividad como el "espacio y proceso en que los individuos construyen una imagen de sí, de los otros y del mundo en el contexto de sus experiencias sociales", es decir, la subjetividad tiene una dimensión individual pero ésta se encuentra arraigada en lo social. De ahí que el bienestar subjetivo no sea exclusivamente una evaluación cognitiva de logro o satisfacción individual sino también una satisfacción con el entorno social y específicamente con el acceso de las personas a oportunidades. 
todas las alternativas posibles, todas ellas valoradas como posibles: "En definitiva, el vínculo entre progreso y bienestar subjetivo requiere de constatar una felicidad reflexivamente fincada, no cualquier felicidad" (Millán, 2011:25). ${ }^{9}$

\section{Bienestar SUbJeTIVO y POlíticas PÚBlicas}

En este apartado se hace un análisis de las principales aportaciones y debates de la literatura académica en relación con la utilidad del enfoque de bienestar subjetivo para la política pública. El propósito es dar respuesta a las siguientes preguntas: (a) ¿Cuál es la utilidad del enfoque de bienestar subjetivo para la política pública? ¿Qué herramientas conceptuales se han desarrollado desde el enfoque de bienestar subjetivo que sean de utilidad para las políticas?; (b) ¿Cuáles son los principales factores con los que está asociado el bienestar subjetivo? Y considerando dichos factores, ¿cuáles son los ámbitos o tipos de política pública que se pueden beneficiar del estudio del bienestar subjetivo?, y finalmente, (c) ¿Cuáles son los límites, retos y alcances de la contribución del estudio del bienestar subjetivo a la política pública?

\section{UNA MIRADA DIFERENTE PARA ENTENDER Y MEDIR EL COMPORTAMIENTO HUMANO}

Uno de los principales aportes del enfoque del bienestar subjetivo a las ciencias sociales y a la comprensión sobre la dinámica social es que ha ofrecido evidencia que parece contradecir la teoría económica tradicional sobre el comportamiento humano. Por ello, algunos de los hallazgos del análisis del bienestar subjetivo se presentan bajo la forma de aparentes paradojas.

\section{Ingreso y bienestar subjetivo: de paradoja en paradoja}

La primera y más conocida de estas paradojas es la de Easterlin, acuñada con el nombre de quien identificó en 1974 la aparentemente contradictoria relación entre ingreso y bienestar subjetivo: Richard Easterlin. La "Paradoja de Easterlin" postula que a medida que los países aumentan su riqueza, sus niveles promedio de bienestar subjetivo no se incrementan o lo hacen con rendimientos decrecientes respecto del

9 Énfasis puesto en el original. 
ingreso (Easterlin, 1974). Se han dado al menos tres explicaciones a esta paradoja: primero, una vez que las necesidades básicas están satisfechas, las aspiraciones de mayor ingreso crecen tanto como el ingreso mismo, disipando así el efecto inicial que un ingreso creciente pueda tener sobre la satisfacción individual. Segundo, existe también un efecto de adaptación a un mayor (o menor) ingreso que hace que el bienestar subjetivo de las personas se mantenga en niveles relativamente constantes, sin verse afectado por aumentos en el ingreso. $\mathrm{Y}$ una tercera explicación es que el bienestar subjetivo no sólo se ve afectado por el ingreso absoluto, sino también por el ingreso relativo: el ingreso de las personas en comparación con el ingreso de aquellos que forman parte del grupo social de referencia, es decir, aunque el ingreso de una persona aumente (o disminuya) en el tiempo, esto no es lo único que incide en su nivel de satisfacción, también importa si el ingreso de las personas que integran el grupo social de referencia crece (o disminuye). ${ }^{10}$

Como en el caso de la Paradoja de Easterlin, la "Paradoja del crecimiento infeliz" también parece contradecir la lógica del análisis económico clásico. La Paradoja del crecimiento infeliz plantea que el bienestar subjetivo se deteriora con el crecimiento económico, específicamente, el crecimiento del ingreso per cápita parece estar asociado en algunos contextos con reducciones en el nivel de satisfacción de vida de los individuos (Lora, 2008a:48). Esta relación se aprecia sobre todo en dos tipos de países, aquellos cuyo ingreso per cápita está por arriba del promedio global y los que crecen a un ritmo más rápido que la tasa global promedio (no obstante, esta relación no se presenta en naciones pobres o con bajas tasas de crecimiento) (Graham, 2009). Explicaciones de la Paradoja del crecimiento infeliz apuntan nuevamente hacia la importancia de las expectativas o aspiraciones en la relación entre ingreso y satisfacción: mayores tasas de crecimiento elevan las expectativas y aspiraciones de los individuos, lo que afecta la evaluación que hacen las personas sobre su vida y nivel de satisfacción (Lora, 2008a). Otra explicación es que un ritmo acelerado de crecimiento, a pesar del aumento en el ingreso, también reduce el tiempo destinado a otros dominios vitales, diferentes al trabajo productivo, que afectan sensiblemente al bienestar subjetivo, como el ocio, la familia o las relaciones con otras personas. Asimismo, la reestructuración del mercado laboral

10 La importancia de las comparaciones con otras personas y entre diferentes aspectos de la vida han sido analizadas y reconocidas en la sociología. Ver Rojas (2008) para una revisión sobre la importancia de los grupos de referencia para el bienestar subjetivo desde la visión sociológica. 
y de las actividades económicas que el crecimiento económico puede generar, hace que surjan inseguridades laborales que inducen estrés y afectan el bienestar subjetivo de las personas (Graham, 2010).

La tercera de las paradojas que aquí se comentan es la acuñada por Carol Graham (2009) como la "Paradoja del campesino feliz". La evidencia empírica indica que, en general, al interior de los países los sectores pobres muestran niveles de satisfacción y bienestar subjetivo mayores que los que se esperaría para su nivel de ingreso e incluso llegan a ser superiores a los de personas con altos ingresos (Graham y Pettinato 2002). Como en las paradojas previas, las explicaciones son diversas e ilustran la complejidad de la relación entre ingreso y bienestar subjetivo: puede ser que los pobres sean "naturalmente" alegres y satisfechos con su vida y puede ser también que los pobres experimentan un efecto de adaptación a su condición de bajos ingresos, con bajas expectativas o aspiraciones de desarrollo, lo que a su vez puede restringir sus posibilidades de encontrar salidas de la pobreza (Graham 2009). La paradoja del Campesino feliz y la investigación sobre bienestar subjetivo en general sugieren que este enfoque puede ayudar a profundizar en la comprensión sobre la pobreza. Como lo advierten Graham (2010) y Rojas (2004), no es poco frecuente que el bienestar de quienes han dejado la pobreza se vea afectado por la inseguridad laboral y económica en general y el riesgo asociado de caer de nuevo en la pobreza, situación que es característica de países de América Latina. Un análisis sustentado en el ingreso difícilmente revelaría la vulnerabilidad de este sector de la población, mientras que la investigación sobre bienestar subjetivo muestra que sí hay un efecto negativo importante en la satisfacción de las personas y que esto puede incidir en la posibilidad de que quienes salgan de la pobreza permanezcan fuera de ella (Graham y Pettinato, 2002). ${ }^{11}$

El análisis de la relación entre ingreso y bienestar subjetivo, plasmado a grandes rasgos en las líneas previas, ilustra las posibilidades y utilidad del enfoque de bienestar subjetivo para comprender, de forma más amplia, el comportamiento humano, específicamente en su relación con el ingreso. En la economía, diversos autores han enfatizado la importancia del enfoque de bienestar subjetivo para presentar alternativas explicativas más solidas sobre la forma en que se comportan las personas y su relación con el ingreso (Stutzer y Frey, 2010; Helliwell y Barrington,

11 Los hallazgos de Palomar (2004) también son relevantes para la comprensión de las dinámicas de la pobreza, específicamente en México, desde una perspectiva psicológica. 
2010; Becchetti y Pelloni, 2011; Graham, 2009, entre otros). Al analizar el comportamiento humano, la doctrina económica clásica argumenta que la mejor manera de comprenderlo es a partir de las preferencias reveladas por las personas en sus decisiones de consumo, asumiendo, entre otras cosas, el acceso a información completa sobre los atributos de los bienes y servicios que desean consumir y el interés de los individuos en maximizar su beneficio. Los estudios sobre bienestar subjetivo sugieren que esta manera de analizar el comportamiento humano no siempre es la más acertada y puede dificultar la comprensión sobre por qué las personas deciden como lo hacen. Las preferencias declaradas o reportadas (a partir de encuestas e instrumentos de consulta directa) como las que se obtienen al preguntarle a las personas sobre su satisfacción de vida o su felicidad, arrojan luz en ámbitos no explorados previamente (Stutzer y Frey, 2010; Helen y Ormerod, 2007). La investigación sobre bienestar subjetivo permite identificar factores no-pecuniarios que para las personas pueden ser tan importantes o más que el ingreso, permite hacer comparaciones sobre la importancia relativa de esos factores y establecer puntos de contraste con mediciones basadas en el ingreso (Graham, 2010:15).

\section{El precio sombra: herramienta para iluminar la valuación de bienes públicos}

El enfoque del bienestar subjetivo ha venido desarrollando herramientas de análisis que son útiles para la hechura de políticas públicas. Aquí se destacan dos: el análisis de valor o precio sombra (shadow-value analysis) y las herramientas de medición del bienestar subjetivo.

En su toma de decisiones, los gobiernos deben analizar los costos y beneficios de las opciones de política pública a su alcance. Ello supone, entre otros aspectos, valuar los beneficios y costos derivados de la provisión de bienes y servicios públicos. La valuación de los bienes y servicios públicos implica diferentes retos, dado que este tipo de bienes y servicios no siempre se intercambian en el mercado y no existe completa claridad sobre el precio al que los actores económicos están dispuestos a intercambiarlos. La investigación sobre bienestar subjetivo ha desarrollado un método de análisis para hacer valuaciones de este tipo de bienes: el análisis de valor o precio sombra, que representa una opción a las metodologías basadas en preferencias reveladas (ver, entre otros: Clark y Oswald, 2002). Este método permite estimar el precio de un bien público a partir del efecto positivo 
o negativo que el acceso o la pérdida de dicho bien tiene en el bienestar subjetivo de la persona, estimando, por ejemplo, el ingreso que una persona debería recibir para recuperar su bienestar subjetivo a niveles previos a los de la pérdida de un bien público. El método también permite estimar cuál es el beneficio pecuniario que se logra cuando una persona disfruta de un bien público en función del incremento que obtiene en su bienestar subjetivo al adquirir dicho bien.

Rojas y Elizondo-Lora (2011) utilizan el método de precio sombra para estimar el valor monetario de una enfermedad, en función de su afectación al bienestar subjetivo. Los autores parten de dos supuestos: que la presencia de enfermedad deteriora la satisfacción de vida de las personas y que un aumento en el ingreso mejora la satisfacción de vida. A partir de estos supuestos calculan qué nivel de ingreso compensaría la enfermedad de una persona de manera que su nivel de satisfacción con su estado de salud permaneciera constante, es decir, regresara a niveles previos a la enfermedad. Como lo señalan los autores, esta forma de estimar el valor monetario de la enfermedad puede interpretarse también como el valor monetario de los beneficios de programas que busquen corregir o evitar un problema de salud. Este método ha sido utilizado también para valuar la contaminación del aire (Welsh, 2006), los desastres ocasionados por inundaciones (Luechinger y Raschky, 2009), el efecto pernicioso del ruido de aeropuertos (Van Praag y Baarsma, 2005) y el terrorismo (Frey et al., 2009), entre otros. A pesar de la utilidad de este método de valuación de costo-beneficio, su principal límite, nada menor, es que las compensaciones monetarias tienen un efecto menor en el bienestar subjetivo de individuos con mayores niveles de ingreso, porque requieren de mayor compensación para aumentar la misma cantidad de satisfacción que requeriría una persona con menor ingreso -dados los rendimientos decrecientes que provoca el efecto de adaptación-(Becchetti y Pelloni, 2011).

\section{Métodos de medición del bienestar subjetivo}

Como se ha mencionado antes en este trabajo, el estudio del bienestar subjetivo ha desarrollado herramientas de medición para captar, de forma directa, el nivel de satisfacción de vida y felicidad declarado por las personas. Las encuestas son una de las herramientas analíticas en las que más se apoya este enfoque y en ellas se han empleado diferentes formas de preguntar a los individuos sobre su nivel de satisfacción, 
así como sus experiencias positivas y negativas. Algunos autores se refieren al uso de las encuestas como "evaluación retrospectiva", dado que permiten conocer, a partir de una escala de menor a mayor satisfacción ${ }^{12}$, qué tan satisfechas se sienten las personas con su vida, lo que supone una valoración de tipo cognitivo y retrospectivo (Bok, 2010). También, en las encuestas se incluyen preguntas que indagan sobre el componente afectivo del bienestar subjetivo, es decir, qué tan feliz se sienten las personas en el momento en que se levanta la encuesta.

Además de las encuestas, se ha desarrollado otras herramientas para medir el bienestar subjetivo de los individuos. Una de ellas es el "muestreo de experiencias" (experience sampling), que consiste en preguntar a las personas, en varios momentos del día, sus experiencias y la satisfacción que les producen. Se usan preguntas sencillas, planteadas con regularidad y cuyas respuestas están menos determinadas por la memoria y el juicio que otros métodos como la evaluación retrospectiva. La limitación de este método es que puede ser muy costoso y no es fácil encontrar un número suficiente de personas dispuestas a participar en ejercicios de este tipo y que sea representativo de la población bajo estudio (Bok, 2010). Otro método de medición es el de "reconstrucción diaria", que consiste en preguntar a las personas qué hicieron el día previo, y se les pide que describan su estado de ánimo durante cada actividad realizada, lo que permite identificar, en un ejercicio de varios días, patrones y asociaciones entre actividades realizadas y niveles de satisfacción y felicidad.

Para algunos estudiosos del tema (Johns y Ormerod, 2007), sólo los estudios tipo panel o longitudinales, en los que se da seguimiento y se aplica una batería de preguntas a los mismos individuos durante periodos de tiempo más o menos extendidos, permiten obtener resultados confiables de correlaciones entre bienestar subjetivo y diferentes dominios de vida de las personas, evitando el sesgo de medición que puede derivarse de recurrir a la memoria y a la reflexión sobre eventos sucedidos en el pasado (evaluación retrospectiva), o de las cambiantes emociones cotidianas (muestreo de experiencias y reconstrucción diaria).

Dos formas adicionales de medir el bienestar subjetivo, que sólo se mencionan pero sobre las que no se profundiza aquí, se encuentran en la neurofisiología, que

12 Comúnmente se emplean dos tipos de escalas, la Cantril, que va del 1 a 10 y la Likart, que va de 1 a 7 , en ambos casos de menor a mayor satisfacción. Además de estas escalas numéricas existen otras que ofrecen de tres a cinco opciones de respuesta que pueden ir de muy satisfecho/feliz a nada satisfecho/feliz. 
permiten correlacionar la satisfacción de vida de las personas con técnicas de encefalografía y neuro-imagenología, y en la genética y la bioquímica, que indaga en qué medida la felicidad está parcialmente determinada por la herencia y la influencia que la genética tiene en la liberación de transmisores químicos en el metabolismo, asociados con estados de felicidad y satisfacción (De Neve et al., 2011).

\section{FACTORES Y DIMENSIONES DE VIDA ASOCIADOS CON EL BIENESTAR SUBJETIVO}

En este apartado se hace referencia a estudios sobre el bienestar subjetivo en diferentes dimensiones de la vida de las personas y ámbitos de análisis. El propósito de este apartado es ilustrar cuáles son los tipos de política pública que podrían beneficiarse de los hallazgos y resultados de los estudios realizados desde el enfoque de bienestar subjetivo.

\section{Política económica: desempleo, inflación e impuestos}

El desempleo y su relación con la inflación han sido áreas que han generado interés en la literatura sobre bienestar subjetivo. Los resultados de la investigación indican que el efecto negativo y perdurable que tiene el desempleo en el bienestar subjetivo de las personas es varias veces superior al que provoca la pérdida de ingreso asociada con la falta de empleo o con la inflación. En promedio, un cambio de $1 \%$ en la tasa de desempleo tiene un efecto negativo en la satisfacción de vida de al menos el doble que el efecto que produce un aumento de $1 \%$ en la tasa de inflación (Dolan, Peasgood y White, 2008, en: OCDE, 2011). Estos resultados han llevado a suponer que, en materia de política económica, los gobiernos deberían inclinarse a favor de políticas expansivas que generen empleo aunque también induzcan a la inflación, dado el efecto más pernicioso de esta última en la satisfacción de vida de las personas (Blanchflower, 2007).

La investigación ha identificado otro aspecto en la relación entre desempleo y bienestar subjetivo que los enfoques tradicionales de la economía deberían considerar. Las pérdidas de bienestar subjetivo que se experimentan por el desempleo afectan no sólo a quienes perdieron su trabajo, sino a otras personas en su entorno, incluso a aquellas que sí cuentan con un puesto de trabajo (Stutzer y Frey, 2010). La gente que sí tiene empleo también se ve afectada de forma negativa en su bienestar subjetivo cuando las tasas de desempleo son altas, en parte por el 
efecto que tiene en la inseguridad económica y por la percepción de una mayor probabilidad de pérdida del empleo.

En materia de impuestos, Robert Frank (1999) ha hecho una controvertida propuesta para establecer un impuesto progresivo al consumo que elimine el efecto pernicioso del gasto en los llamados bienes posicionales, que son aquellos que las personas buscan adquirir para mejorar su estatus o posición social. Frank argumenta que este tipo de consumo posicional introduce a los individuos en una carrera por el estatus que impacta negativamente en su bienestar subjetivo al reducir el tiempo y los recursos disponibles para otras actividades que pudieran generar mayor satisfacción y bienestar. Por su parte, Weisbach (2007) también ha explorado las posibilidades que ofrece el enfoque de bienestar subjetivo para la política impositiva y concluye que si bien el grado de desarrollo de la investigación en la materia aún no permite derivar guías claras para la política, sí conduce a rutas de reflexión y análisis que deben tomarse en cuenta.

\section{Instituciones: democracia, calidad del gobierno, corrupción y administra- ción de justicia}

¿Los gobiernos democráticos contribuyen a la felicidad de la población o la gente que es feliz apoya la democracia y contribuye así a mejorar la calidad del gobierno? Al analizar la relación entre democracia y bienestar subjetivo, algunos autores, como Ronald Inglehart (2006), han encontrado que ambos efectos ocurren: el bienestar influye en la democracia y viceversa, aunque el efecto más significativo es el que las personas felices tienen sobre la calidad del gobierno ${ }^{13}$.

En el ámbito de las instituciones democráticas de gobierno se ha identificado que existen dos instituciones básicas que afectan el bienestar subjetivo de la población: la democracia directa y el federalismo (Frey y Stutzer, 2010). Las estimaciones econométricas realizadas sugieren que existen correlaciones estadísticamente significativas entre bienestar subjetivo, referéndum, plebiscito y autonomía de las instituciones de gobierno locales en Suiza. Destaca que la población parece darle especial importancia a la posibilidad de participar en procesos decisorios públicos

13 Otros investigadores también han explorado las relaciones entre democracia, bienestar subjetivo y desarrollo humano (Temkin y Del Tronco, 2006), y felicidad y democracia en América Latina (Graham y Pettinato, 2002). 
que les afectan. Es decir, tan importantes son los resultados de la política como el proceso de construcción de la misma y la participación de la población en ella. Al explorar si existe algún tipo de asociación entre bienestar subjetivo y calidad del gobierno, medido a partir de variables como las capacidades regulatorias, el Estado de Derecho, el control de la corrupción y la efectividad gubernamental, se ha identificado que la relación entre calidad gubernamental y bienestar subjetivo es independiente del tamańo del gobierno (Ott, 2010) ${ }^{14}$. Asimismo, las capacidades técnicas de los gobiernos (regulatorias, de control de la corrupción, preservación del Estado de Derecho, efectividad gubernamental) son apreciadas en sí mismas por la población y no sólo por los resultados que pueden generar, como competencia económica o el respeto a la ley (Ott, 2010).

También en el marco de las instituciones de gobierno, específicamente en la relación entre Estado de Bienestar y bienestar subjetivo, se ha encontrado que en los países con Estado de Bienestar de tipo universalista la gente tiene niveles más altos de bienestar subjetivo (Rothstein, 2010). Sin embargo, dos variables son importantes en esta relación: la corrupción y la confianza social. Considerando estas variables, los países pueden identificarse en dos grupos: por un lado están aquellos que tienen un Estado de Bienestar grande y universalista, bajos niveles de corrupción, confianza social extendida y mayores grados de bienestar subjetivo, y por otro lado se encuentran los países con un Estado de Bienestar pequeño y no universalista, con mayores niveles de corrupción, baja confianza social y bajos niveles de satisfacción (Rothstein, 2010). Esta evidencia estaría contradiciendo los argumentos que señalan que el Estado de Bienestar universalista y grande es, en general, corrupto e invasivo en la vida privada, y por lo tanto pernicioso para el bienestar subjetivo. En este sentido, la corrupción y la confianza social son variables que parecen tener un fuerte poder modulador en la relación entre Estado de Bienestar (sea grande o pequeño) y bienestar subjetivo. Dado que no es posible establecer con claridad la dirección de la causalidad entre estas variables es necesario tomar con cautela estos resultados en cuanto a sus implicaciones de política pública.

Finalmente, en el ámbito de las instituciones de gobierno, existen algunos estudios destacables en la materia de administración de justicia. Bronsteen et al., (2010)

14 Lo que también sugiere que la propia calidad del gobierno no está necesariamente asociada con el tamańo del aparato gubernamental. 
argumentan que el sistema penal de Estados Unidos podría estar equivocando los supuestos con los cuales establece penas tales como tiempo de prisión y monto de fianzas, y su proporcionalidad, a juzgar por el impacto directo que estas tienen en el bienestar subjetivo de las personas. Los resultados se sustentan en gran parte en el análisis del efecto de adaptación, ya discutido en líneas previas, cuya importancia se ha destacado en los estudios de bienestar subjetivo. Las personas parecen adaptarse con relativa facilidad a una reducción en su riqueza, derivada, por ejemplo, del pago de una fianza, e incluso también se pueden adaptar a vivir en prisión. Pero es mucho más difícil la adaptación a las condiciones de vida que se les presentan a los ex presidiarios una vez que dejan la prisión (sin importar el tiempo de reclusión), tales como desempleo, enfermedades y pérdida de vínculos sociales. Esto sugiere que aumentar o disminuir el tiempo de prisión o el monto de las fianzas tiene un efecto punitivo inmediato en las personas pero quizá irrelevante en cuanto al castigo más significativo, que constituye el simple hecho de haber estado preso.

\section{Cohesión y vínculos sociales}

Uno de los ámbitos que mayor interés ha generado entre los estudiosos del bienestar subjetivo es el de cohesión y vínculos sociales, que incluye factores tales como capital social, bienes relacionales, uso del tiempo, gasto pro social y prácticas religiosas (no necesariamente la creencia en una fe o doctrina). En general, los estudios en este ámbito señalan que existe una fuerte correlación entre la satisfacción de vida y felicidad de las personas y la cohesión, los vínculos sociales y las actividades que suponen establecer o estrechar lazos entre individuos o grupos (Helliwell et al., 2012).

Se ha encontrado que el gasto pro social, que es aquel destinado a ayudar a otros, también está fuertemente asociado con mayores niveles de bienestar subjetivo, con una relación causal clara: el gasto pro social conduce a una mayor felicidad en las personas que realizan ese tipo de gasto. Este resultado parecería cuestionar el supuesto de la doctrina económica clásica sobre el interés propio como motivación primigenia del individuo (Aknin et al., 2010).

Hay estudios en los que se ha indagado la importancia de factores diferentes al ingreso en el empleo y su correlación con el bienestar subjetivo de las personas (Helliwell y Huang, 2008). Se ha encontrado que existe una asociación significativa 
entre la felicidad y los rasgos no financieros del empleo, especialmente la confianza entre las personas en el lugar de trabajo, de manera que el ofrecimiento de un sueldo y prestaciones atractivas pueden ser factores determinantes para optar por un empleo, pero serían menos decisivos para permanecer en él.

La literatura sobre bienestar subjetivo también ha encontrado una ruta de convergencia con la literatura sobre bienes relacionales ${ }^{15}$, señalando que existe una relación positiva entre ambos. Por ejemplo, Becchetti et al. (2009) y Bartolini et al. (2009) argumentan que la aparente tendencia decreciente en el nivel de felicidad de la población de Estados Unidos en décadas recientes se puede explicar, entre otros factores, por el declive del capital social que también se ha apreciado en ese país, principalmente los componentes relacionales de dicho capital.

Finalmente, en el ámbito de la religión, algunos autores seńalan que la asistencia a servicios religiosos representa una suerte de seguro para mantener constantes los flujos y niveles de felicidad frente a impactos negativos en el ingreso. Una situación similar ocurre entre la asistencia a servicios religiosos y reducción inesperada en los niveles de consumo de las personas (Dehejia et al., 2005).

\section{Acceso a bienes públicos: agua, educación y salud}

Diversos autores han estudiado ámbitos relevantes de la política social desde el enfoque de bienestar subjetivo. Por ejemplo, una investigación realizada en áreas rurales de Marruecos indica que la gente que carece de agua potable en su hogar, aunque tenga acceso a fuentes públicas de agua, estaría dispuesta a hacer una inversión financiera sustancial para tener acceso al recurso hídrico en su casa, a juzgar por el incremento en los niveles de bienestar subjetivo que se alcanzan cuando se tiene agua potable en el hogar (Devoto et al., 2011). Tener agua en la vivienda supone dedicarle menos tiempo a obtenerla en lugares públicos y destinar ese tiempo al ocio u otras actividades. También puede reducir las tensiones derivadas del acceso al acuífero. Una de las implicaciones de los hallazgos de esta

15 Los bienes relacionales son bienes para los que se requiere la participación de al menos dos personas, y que se caracterizan en que la inversión, producción y consumo de estos bienes coincide o es casi simultánea. Los bienes relacionales son los que se adquieren por medio de las relaciones, el apoyo emocional, la solidaridad (Becchetti y Pelloni, 2011:11-12). 
investigación es que ahí donde no es posible abastecer de agua potable a todos los hogares, una alternativa es facilitar el acceso al crédito para que los hogares financien la inversión necesaria para obtener agua potable en el hogar.

En México, en un estudio sobre el acceso al agua en el estado de Yucatán (Guardiola et al., 2011), se ha encontrado que existe una relación positiva y estadísticamente significativa entre el acceso al agua y el bienestar subjetivo, de tal forma que se considera que el acceso al agua debe ser considerado un dominio de vida por su influencia positiva en el bienestar subjetivo (Guardiola et al., 2011). En el contexto regional más amplio de América Latina, Lora et al. (2008b) encuentran que la disponibilidad de agua es uno de los determinantes más importantes de la satisfacción con la vivienda en la región: "la disponibilidad de agua corriente aumenta la probabilidad de satisfacción de las personas con sus viviendas en 34\%" (Lora et al., 2008b:199). Otros estudios (Powell y Sanguinetti, 2010) confirman también que el acceso a servicios básicos como el agua resultan importantes para dar cuenta de la satisfacción de vida en los vecindarios urbanos de América Latina.

En materia educativa, se ha identificado que el aumento en la escolaridad no sólo aumenta las posibilidades de obtener un empleo con mayores ingresos en el futuro. Los efectos de la escolaridad se pueden observar en otros aspectos no pecuniarios, como el aumento en las aspiraciones a empleos de mayor estatus y prestigio, y la competencia que esto genera para ese tipo de empleo. Estos aspectos no asociados al ingreso son al menos tan importantes como los pecuniarios y están relacionados con el bienestar subjetivo y objetivo de las personas (Oreopoulos y Salvanes, 2009).

En el ámbito de la salud, además del estudio de Rojas (2011), ya referido, sobre la valuación monetaria del efecto de las enfermedades en la satisfacción de vida, otros autores han analizado la correlación entre satisfacción de vida y salud percibida o subjetiva (percepción de la persona sobre su estado de salud) y aspectos tales como el ingreso, el crecimiento, la salud objetiva y la edad (Deaton, 2008). A partir de los resultados obtenidos, se ha planteado que la falta de correlación entre las medidas de satisfacción de vida y de salud sugiere que la felicidad y la salud reportada no pueden ser consideradas como indicadores sintéticos útiles de bienestar humano para realizar comparaciones internacionales, por lo que deben ser complementados por otros indicadores. 
LimitACIONES, RETOS Y ALCANCES DEL ENFOQUE DE BIENESTAR SUBJETIVO

En esta sección presentó algunos de los principales retos y limitaciones del uso del enfoque de bienestar subjetivo para el análisis y hechura de políticas públicas. Los retos planteados indican que los hallazgos y resultados del estudio sobre satisfacción de vida y felicidad deben tomarse con cautela al tratar de llevarlos de forma directa al ámbito de la política pública.

De acuerdo con Bok (2010:40), la principal debilidad del estudio del bienestar subjetivo es que se trata de un ámbito de estudio muy reciente para el conjunto de posibles líneas de exploración en las que se puede trabajar: "hay cientos de estudios en la materia, pero muchas más fuentes posibles de bienestar e insatisfacción”. Lo que los resultados de los estudios han arrojado es que existe correlación entre el bienestar subjetivo y otros aspectos, pero no existe claridad sobre la dirección de la relación causal, lo que es un asunto clave cuando se trata de derivar implicaciones y recomendaciones de política. Si la política pública es, como lo propusieron Pressman y Wildavsky (1973), una cadena causal entre las condiciones iniciales y las futuras consecuencias, es decir una hipótesis causal entre una acción (la política pública) y un efecto (el resultado o impacto deseado por la política), entonces las dificultades para establecer la dirección de la causalidad es un reto importante para los estudios sobre bienestar subjetivo.

Una crítica presente en la literatura sobre bienestar subjetivo tiene que ver también con la validez y confiabilidad de las mediciones sobre satisfacción de vida y felicidad. ¿En qué medida los métodos de medición de bienestar subjetivo capturan lo que se quiere medir? ¿En qué grado las mediciones logran controlar los sesgos del contexto o de los propios instrumentos de medición? Para mejorar la precisión de las mediciones sobre satisfacción de vida y felicidad los investigadores han recurrido a diferentes alternativas para confirmar los resultados. Por ejemplo, las evaluaciones de bienestar subjetivo se han correlacionado con la opinión de amigos y familiares sobre qué tan feliz están las personas incluidas en una investigación o encuesta, mostrando altos niveles de correlación (Bok, 2010). Asimismo, la literatura en el ámbito de la salud ha mostrado hallazgos que establecen relaciones significativas y positivas entre los niveles de felicidad declarada y reacciones físicas saludables. En la neurociencia se han realizado estudios que han 
mostrado que el bienestar, el placer o la satisfacción declaradas están relacionadas con la misma actividad cerebral (Becchetty y Pelloni, 2011).

La confiabilidad de las mediciones de bienestar subjetivo también encuentra retos en aspectos como la afectación por factores de contexto de las personas encuestadas sobre su nivel de satisfacción de vida o felicidad. Algunos de esos factores de contexto incluyen el lugar en el que se ubica la pregunta en el cuestionario, el fraseo de la pregunta que se hace, la escala o rangos de respuesta que se ofrezca al encuestado, sucesos recientes y coyunturales que afecten al entrevistado y por tanto su respuesta (Graham, 2010:11-12). No obstante, la mayor parte de estos errores se neutralizan en la agregación global de los resultados de las encuestas.

Otro reto en términos de medición es el que Sen (2005, citado en Becchetti y Pelloni, 2011) ha sintetizado como la paradoja del "Esclavo feliz", aspecto clave para la política pública. Los estudios del bienestar subjetivo no deberían caer en la trampa de considerar la satisfacción de vida y la felicidad como único criterio de decisión, por el riesgo de legitimar de forma implícita la explotación y las condiciones de pobreza en aquellos casos en que se presente el efecto de adaptación a la miseria u otras condiciones éticamente inaceptables y en que las personas parezcan ser, a pesar de todo, felices. El reto es evitar que el bienestar subjetivo se convierta en un nuevo indicador sintético del progreso sin considerar la multiplicidad de factores que inciden en la propia satisfacción y felicidad de las personas. El uso correcto debería ser el tomar en cuenta una amplia variedad de factores e indicadores que ayuden a comprender si las políticas públicas crean las condiciones para maximizar el bienestar individual y social bajo las restricciones de la sustentabilidad ambiental y la necesidad de crear valor económico. Como lo indican Becchetti y Pelloni (2011), el enfoque de bienestar subjetivo va más allá de la separación entre disciplinas y requiere de la participación de la psicología, la sociología, la economía, la neurociencia, entre otras, para comprender las consecuencias de la acción económica en el bienestar.

A pesar de los retos mencionados, los niveles de confiabilidad, validez y rigor en las mediciones de bienestar subjetivo han permitido ofrecer una alternativa analítica a perspectivas tradicionales y han abierto caminos de indagación útiles para las ciencias sociales. En el ámbito de la política pública, la investigación sobre felicidad puede ayudar, entre otros aspectos, a definir prioridades al llamar la 
atención sobre problemas públicos que desde otros enfoques pueden ser pasados por alto, puede apoyar a identificar causas específicas de malestar o infelicidad, puede ayudar a conocer el impacto de leyes o programas y comparar la situación de bienestar de las personas afectadas, antes y después de que haya sido introducida la ley o medida gubernamental, y también puede ayudar a identificar los efectos en el bienestar de cambios institucionales que modifican la relación entre ciudadanos y autoridades (por ejemplo, mecanismos de democracia directa como el plebiscito y el referéndum) (Bok, 2010). Así, un efecto posible es que la discusión del bienestar subjetivo pueda ayudar a modificar el balance sobre lo que se considera importante medir, lo que a su vez puede cambiar la naturaleza y el enfoque del análisis y estudio de las políticas públicas entre los encargados de su diseño y ejecución, y quizá entre los propios beneficiarios de las políticas.

\section{CONSIDERACIONES FINALES}

Como se ha argumentado a lo largo de este trabajo, el enfoque de bienestar subjetivo puede ser de utilidad para la política pública en diversos temas y aspectos. En primer lugar, como se puede apreciar desde los inicios del estudio empírico del bienestar subjetivo en la década de 1920, este enfoque ofrece nuevas formas de poner a prueba supuestos básicos del análisis económico y social sobre el comportamiento humano. En segundo lugar, provee herramientas de análisis que ofrecen una perspectiva diferente y complementaria a mediciones y enfoques tradicionales sobre los aspectos que más importan a la población en su proceso de desarrollo. En tercer lugar, el enfoque de bienestar subjetivo dirige la atención hacia un conjunto de reflexiones necesarias sobre las implicaciones del estudio de la felicidad y la satisfacción de vida en diferentes ámbitos de la acción pública y gubernamental.

Las limitaciones y los retos del enfoque de bienestar subjetivo como fuente de conocimiento, análisis y recomendaciones para la política pública están relacionados, en algunos casos, con el carácter relativamente novel de este enfoque. Pero si bien estas limitaciones y retos no son menores, la comunidad de especialistas e interesados en la materia, incluyendo ahora los gobiernos, han desarrollado diversas herramientas para mejorar la confiabilidad, validez y alcances de este campo de estudio. 
Una de las ideas centrales de este trabajo, particularmente en lo que se refiere al uso del enfoque de bienestar subjetivo en la política pública, es que no se trata necesariamente de que la política pública tenga como objetivo principal que todas las personas alcancen la mayor felicidad y satisfacción posibles. Se trata, más bien, de mejorar las condiciones que favorezcan al bienestar subjetivo así como encontrar formas de reducir la brecha entre los objetivos de desarrollo y bienestar de la política pública, por un lado, y el bienestar subjetivo de la población, por el otro, a partir de una mejor comprensión de las preferencias y comportamientos de los individuos y lo que afecta la satisfacción de las personas con su vida. Más que elevar los niveles de felicidad y satisfacción de las personas, en sí mismo importante, la política pública puede aprovechar los resultados y las herramientas analíticas que se han desarrollado desde el enfoque de bienestar subjetivo para mejorar la comprensión del comportamiento humano que busca transformar, considerar perspectivas no analizadas, ponderar decisiones e instrumentos de medición de mejor forma y tener más presente que el crecimiento, el desarrollo y el progreso están influidos tanto por la genética como por la interacción cotidiana y en apariencia errática o impredecible de los individuos. Como lo afirmó Cantril (1965:34), "predicciones más confiables sobre lo que la gente quiere o no quiere, cree o no cree, aceptará o no aceptará, deben ayudar al proceso de creación de nuevas instituciones económicas, sociales y políticas".

\section{REFERENCIAS BIBLIOGRÁFICAS}

Aknin, Lara (2010). Prosocial spending and well-being: Cross-cultural evidence for a psychologocal universal, Documento de trabajo 16415, Buró Nacional de Investigación Económica, Estados Unidos.

Angner, Erik (2011). "The evolution of eupathics: the historial roots of subjective measures of wellbeing”. The International Journal of Wellbeing, Vol. 1, No 1, pp. 4-41.

Asamblea General de las Naciones Unidas (2011). Happiness: towards an holistic approach to development, Resolución del 13 de julio, aprobada en la sesión del 19 de julio de 2011 por la 65a Asamblea General de las Naciones Unidas, http://www.gnhusa.org/wp-content/ uploads/2011/07/UN-Resolution-on-Happiness-Measures-7-13-2011.pdf

Banco Mundial (2006). Where is the wealth of nations? Measuring capital for the 21st century, Washington, DC, Estados Unidos. 
Bartolini, S. et al. (2009). American decline in social capital and happiness. Is there a linkage?, Universidad de Siena, Italia.

Becchetti, Leonardo y Alessandra Pelloni (2011). What are we learning from the life satisfaction literature? Documento de Trabajo número 2, Ministerio de Economía y Finanzas, Departamento del Tesoro, www.dt.tesoro.it

Becchetti, Leonardo, Elena Giachin Ricca y Alessandra Pelloni et al (2009). On the causal impact of relational goods on happiness. CEIS Working Paper No. 151, Center on Economic and International Studies.

Bentham, Jeremy (1789). Introducción a los principios de la moral y la legislación, publicado en 1907 por Oxford: Clarendon Press, http://www.econlib.org/library/Bentham/bnthPML.html

BioMed Central (2011, julio 25). "Global depression statistics" en: ScienceDaily: http://www.sciencedaily.com /releases/2011/07/110725202240.htm

Blanchflower, David (2007). Is Unemployment More Costly Than Inflation?, Documento número 13505, Buró Nacional de Investigación Económica, Estados Unidos.

Bok, Derek (2010). The politics of happiness: What government can learn from the new research on well-being, Princeton University Press, Estados Unidos.

Bok, Sissela (2010). Exploring happiness. From Aristotle to Brain Science, Yale University Press, Estados Unidos.

Angner, Erik (2011). "The evolution of eupathics: the historial roots of subjective measures of wellbeing". The International Journal of Wellbeing, Vol. 1, No 1, pp. 4-41.

Bronsteen, John; Buccafusco, Christopher y Masur, Jonathan (2010). Happiness and Punishment, Chicago-Kent College of Law, Serie de Documentos de Investigación en Ciencia y Tecnología http://www.ssrn.com/link/Chicago-Kent-Law-STI.html.

Cantril, H. (1965). The pattern of human concerns, Rutgers University Press, Estados Unidos.

Clark, Andrew y Oswald, Andrew (2002). A simple statistical method for measuring how life efects affect happiness, Universidad de Warwick, Reino Unido.

Cobb, Clifford W. y Rixford, Craig (1998). Lessons learned from the history of social indicators, Redefining Progress, San Francisco, California, Estados Unidos, www.rprogress.org

Deaton, A. (2008). "Income, Health, and Well-Being around the World: Evidence from the Gallup World Poll”, Journal of Economic Perspectives, Vol. 22, No 2, pp. 53-72.

Dehejia, Rajeev, et al. (2005). Insuring consumption and happiness through religious organizations, Documento de trabajo número 11576, Buró Nacional de Investigación Económica, Estados Unidos, http://www.nber.org/papers/w11576. 
De Neve, Jan-Emmanuel, et al. (2011). Genes, economics and happiness, Institute for Empirical Research in Economics, Universidad de Zurich, Alemania.

Devoto, Florencia (2011). Happiness on tap: piped water adoption in urban Morocco, Documento de trabajo número 16933, Buró Nacional de Investigación Económica, Estados Unidos, http://www.nber.org/papers/w16933.

Easterlin, Richard (1974). "Does economic growth improve the human lot? Some empirical Evidence", en: David P. A. y M. W. Reder (eds.). Nations and Households in Economic Growth Essays in Honor of Moses Abramovitz, Nueva York, AcademicPress.

Frank, Robert (1999). Luxury Fever: Why money fails to satisfy in an era of excess, Nueva York: Free Press, Estados Unidos.

Frank, Robert, et al. (2009). "The Life Satisfaction Approach to the value of public godos: The case of terrorism”. Public Choice Vol. 138, No 3-4, pp. 317-345.

Graham, Carol (2010). The Challenges of Incorporating Empowerment into the HDI: Some lessons from happiness economics and Quality of Life Research, Human Development Reports, Documento de investigación 20/13, PNUD.

Graham, Carol (2009). Happiness around the world. The paradox of happy peasants and miserable millionaires, Oxford University Press, Nueva York, Estados Unidos.

Graham, Carol y Pettinato, S. (2002). Happiness and hardship: Opportunity and insecurity in new market economies, Washington, The Brookings Institution Press, Washington, DC, Estados Unidos.

Guardiola, J.; F. González-Gómez, A. Lendechy (2011). “The Influence of Water Access in Subjective Well-Being: Some Evidence in Yucatan, Mexico”, Social Indicators Research, Publicado en línea: 27 de agosto del 2011, http://dx.doi.org/10.1007/s11205-011-9925-3

Hart, Hornell (1940). Chart of Happiness, The MacMillan Company, Nueva York, Estados Unidos, http://bit.ly/ul25fA.

Haggart, Blayne (2000). The Gross Domestic Product and Alternative Economic and Social Indicators, Gobierno de Canadá, División de Economía, Canadá, http://bit.ly/RsALBQ

Haybron, Dan (2011). "Happiness”, en: Edward N. Zalta (ed.). The Stanford Encyclopedia of Philosophy http://plato.stanford.edu/archives/fall2011/entries/happiness/ (consultado en octubre de 2012).

Helliwell, John F. y Haifang Huang (2008). Well-being and trust in the work place, Documento de trabajo número 14589, Serie de documentos de trabajo del Buró Nacional de Investigación Económica, www.nber.org/papers/w14589. 
Helliwell, John F. y Haifang Huang, y Christopher P. Barrington-Leigh (2010). Measuring and understanding subjective well-being, Documento de trabajo número 15887, Serie de documentos de trabajo del Buró Nacional de Investigación Económica, www.nber.org/ papers/w15887.

Helliwell, John et al. (2012). World Happiness Report, Earth Institute, Universidad de Columbia, http://bit.ly/PNa8bU.

Inglehart, Ronald (2006). Democracy and Happiness: What causes what?, Documento presentado en la Conferencia sobre Felicidad Humana en la Universidad de Notre Dame, 22-24 de octubre de 2006.

Johns, Helen y Paul Ormerod (2007). Happiness, Economics and Public Policy, The Institute of Economic Affairs, Londres, Reino Unido.

Layard, Richard (2005). Happiness. Lessons from a new science, Penguin Press, Estados Unidos.

Lora, Eduardo (coord.) (2008a). Calidad de vida: más allá de los hechos, Banco Interamericano de Desarrollo y Fondo de Cultura Económica, 2008.

Lora, E., et al. (2008b). "Calidad de vida urbana: más que ladrillos y cemento”, en: Lora, E. (coord.), Calidad de vida. Más allá de los hechos, Banco Interamericano de Desarrollo-Fondo de Cultura Económica.

Luechinger, Simon y Paul Raschky (2009). "Valuing flood disasters using the Life Satisfaction Approach”. Journal of Public Economics, Vol. 93, No 3-4, pp. 620-633.

Bok, Sissela (2010). Exploring happiness. From Aristotle to Brain Science. Estados Unidos: Yale University Press.

Millán, René (2011). “El bienestar como nuevo 'objeto' del progreso. Cinco reflexiones”, pp. 1928, en: Rojas, Mariano (coord.). La medición del progreso y del bienestar. Propuestas desde América Latina, Foro Consultivo Científico y Tecnológico y Consejo Nacional de Ciencia y Tecnología, México.

Oreopoulos, Philip y Kjell G. Salvanes (2009). How large are returns to schooling? Hint: Money isn't everything, Documento de trabajo 15339, Buró Nacional de Investigación Económica, http://www.nber.org/papers/w15339.

Organización para la Cooperación y el Desarrollo Económicos (OCDE), et al. (2007). Declaración de Estambul, 20 Foro Global "Midiendo y Promoviendo el Progreso de las Sociedades", http://www.oecd.org/oecdworldforum/Istanbul

Ott, J. (2010). “Greater Happiness for a Greater Number: some non-controversial options for governments”. Journal of Happiness Studies, Vol. 11, No 5, pp. 631-647. 
Office of National Statistics (2011). Measuring subjective wellbeing for public policy, febrero 2011, Gobierno del Reino Unido, www.ons.gov.uk.

Palomar, J. (2004). Pobreza, recursos psicológicos y bienestar subjetivo, Serie Documentos de Investigación, Universidad Iberoamericana, México.

Powell, A. y P. Sanguinetti (2010). "Measuring Quality of Life in Latin America's Urban Neighborhoods: A Summary of Results from the City Case Studies", en: Lora, E.; A. Powell, B. van Praag y P. Sanguinetti (eds.), The Quality of Life in Latin American Cities: markets and perceptions, Banco Interamericano de Desarrollo y Banco Mundial, Washington, DC, Estados Unidos.

Pressman, Jeffrey y Aaron Wildavsky (1973). Implementation, University of California Press, Estados Unidos.

Rojas, Mariano (2004). Well-being and the complexity of poverty. A subjective Well-being Approach, Research Paper No. 2004/29, World Institute for Development Economics Research, United Nations University, abril 2004.

Rojas, Mariano (2008). Relative income and well-being in Latin America, Facultad Latinoamericana de Ciencias Sociales (Flacso), Sede México y Universidad Popular Autónoma del Estado de Puebla, México.

Rojas, Mariano, Elizondo-Lara, Maikol (2011). "La evaluación de enfermedades. Un enfoque de bienestar subjetivo". El Trimestre Económico, Vol. LXXIX, № 3.

Rothstein, Bo (2010). Corruption, Happiness, Social Trust and the Welfare State: A Causal Mechanisms Approach, Serie de Documentos de Trabajo 2010:9. Universidad de Gothenburg, Instituto de Calidad del Gobierno.

Rowe, Jonathan (2008). “Our Phony Economy”, Harper's Magazine, junio, pp. 17-24.

Seligman, Martin (1991). Learned optimism. Estados Unidos.

Sen, Amartya (1996). "Capacidad y bienestar", en: Nussbaum, Martha y Sen, Amartya (comps.). La calidad de vida, México: Fondo de Cultura Económica.

"Simon Kuznets". The Concise Encyclopedia of Economics. 2008. Library of Economics and Liberty, Consulta hecha por internet el 25 de octubre de 2011: http://www.econlib.org/library/ Enc/bios/Kuznets.html.

Stiglitz, Joseph; Sen, Amartya y Fitoussi, Jean-Paul (2009). Report by the Commission on the Measurement of Economic Performance and Social Progress, <www.stiglitz-sen-fitoussi.fr>.

Stutzer, Alois y Bruno Frey (2010). "Recent Advances in the Economics of Individual Subjecive Well-Being”. Social Research, Vol. 77, No 2, pp. 679-714. 
Temkin, Benjamín y José del Tronco (2006). "Desarrollo humano, bienestar subjetivo y democracia: confirmaciones, sorpresas e interrogantes", Revista Mexicana de Sociología, Vol. 68, No 4, pp. 731-760.

Ura, Karma et al. (2012). A Short Guide to Gross National Happiness Index, The Centre for Bhutan Studies, www.grossnationalhappiness.com.

Van Praag, Bernard y Barbara Baarsma (2005). "Using happiness surveys to value intangibles: The case of airport noise”. Economic Journal, Vol. 115, No 500, pp. 224-246.

Weisbach, David (2007). What Does Happiness Research Tell Us about Taxation? Universidad de Chicago, Estados Unidos.

Welsch, Heinz (2006). "Environment and happiness: valuation of air pollution using life satisfaction data", Ecological Economics, Vol. 58, No 4, pp. 801-813. 